\title{
DETERMINATION OF THE NEUTRON CONTRIBUTION TO THE REM DOSE
}

\author{
by \\ Dale E. Hankins \\ Los Alamos Scientific Laboratory \\ of the \\ University of California \\ Los Alamos, New Mexico
}

BELEAISED FOR ANNOUNCENENT

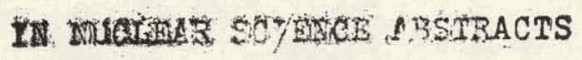

\section{LEGAL NOTICE}

This report was prepared as an account of Government sponsored work. Neither the United States, nor the Commission, nor any person acting on behalf of the Commission:

A. Makes any warranty or representation, expressed or implied, with respect to the accuracy, completeness, or usefulness of the information contained in this report, or that the use of any information, apparatus, method, or process disclosed in this report may not infringe privately owned rights; or

B. Assumes any liabilities with respect to the use of, or for damages resulting from the use of any information, apparatus, method, or process disclosed in this report.

As used in the above, "person acting on behalf of the Commission" includes any employee or contractor of the Commission, or employee of such contractor, to the extent that such employee or contractor of the Commission, or employee of such contractor prepares, disseminates, or provides access to, any information pursuant to his employment or contract with the Commission, or his employment with such contractor. 


\section{DISCLAIMER}

This report was prepared as an account of work sponsored by an agency of the United States Government. Neither the United States Government nor any agency Thereof, nor any of their employees, makes any warranty, express or implied, or assumes any legal liability or responsibility for the accuracy, completeness, or usefulness of any information, apparatus, product, or process disclosed, or represents that its use would not infringe privately owned rights. Reference herein to any specific commercial product, process, or service by trade name, trademark, manufacturer, or otherwise does not necessarily constitute or imply its endorsement, recommendation, or favoring by the United States Government or any agency thereof. The views and opinions of authors expressed herein do not necessarily state or reflect those of the United States Government or any agency thereof. 


\section{DISCLAIMER}

Portions of this document may be illegible in electronic image products. Images are produced from the best available original document. 


\title{
DETERMINATION OF THE NEUTRON CONTRIBUTION TO THE REM DOSE*
}

\author{
by
}

\author{
Dale E. Hankins
}

\begin{abstract}
A description is given of the single-sphere neutron-monitoring instrument and its neutron-energy response. Three years of operating experience with several models of these instruments are described. The limitations for use of the instrument for accelerator-produced neutrons and some of the special applications of the instrument are discussed.
\end{abstract}

\section{INTRODUCTION}

Monitoring stray neutrons with a wide range of energies, such as are found around accelerator shielding, has always presented. a problem. One solution to the problem is to use the $10 \mathrm{in}$. singlesphere monitoring instrument. This instrument has a response approximating the rem-dose curve from thermal to $7.0 \mathrm{MeV}$. The instrument is direct-reading in mrem/hr, requiring no knowledge on the part of the user of the neutron-energy spectrum and no application of factors based on an estimate of the neutron-energy spectrum. In any monitoring situation where scattered neutrons having energies of less than $7.0 \mathrm{MeV}$ are present, this system has proved effective and should be considered.

The single-sphere neutron-monitoring instrument was developed to fill the need of a portable neutron instrument which can be used with all neutron energies simultaneously and has a direct-reading meter to indicate the dose rate in $\mathrm{mrem} / \mathrm{hr}$. The single-sphere instrument meets these requirements within certain limits.

\section{DESCRIPTION OF INSTRUMENT}

The single-sphere instrument is a modification of the Bonner sphere spectrometer ${ }^{1}$ which was developed by the late Dr. T. W. Bonner

\footnotetext{
*Work performed under the auspices of the U. S. Atomic Energy Commission.
} 
of the Rice Institute. The instrument contains a lithium-iodidecrystal detector $4 \mathrm{~mm}$ in diameter and $4 \mathrm{~mm}$ thick, which is more than 80 percent "black" for thermal neutrons. The crystal is coupled to a photomultiplier tube by a $\frac{1}{2}$ in. $0 . d$. quartz or polystyrene lightpipe that is wrapped in aluminum foil and then taped. The detector system is enclosed in a hollow brass tube that gives mechanical support and acts as a light shield. Over the detector system is placed a 10 in. sphere of polyethylene with a hole $41 / 64$ in. in diameter drilled to a depth that will permit the light-pipe to be inserted with the lithium-iodide crystal at the center. The output of the photomultiplier tube is fed through a standard preamplifier and amplifier and then to a scaler or a ratemeter.

Analyses of the response curves published by Bonner for the series of spheres indicate that a $10 \mathrm{in.} \mathrm{sphere} \mathrm{would} \mathrm{have} \mathrm{a} \mathrm{response}$ approximating the rem-dose curve. A sphere of 10 in. diameter was made and its efficiency studied by using thermal neutrons from the Los Alamos Water Boiler Reactor and fast neutrons from the Los Alamos vertical Van de Graaff accelerator. ${ }^{2}$ The response curve which was obtained is given in Fig. 1. From this figure it can be seen that for fast neutrons the instrument response is within \pm 15 percent and for thermal neutrons it is nearly correct ( \pm 4 percent).

After the experimental response curve had been obtained, a series of calculations to determine the response of the instrument in the intermediate region was made using the DSN neutron transport code $^{3}$ and an IBM 704 computer. Recently a new calculation using adjoint transport calculations has been made for the $10 \mathrm{in.} \mathrm{sphere,}$ with the result being almost identical with the previous calculation. The new calculation contained more data points and also extended the energy range to $192 \mathrm{MeV} .^{4}$ The results of this calculation are shown in Fig. 2 .

The single-sphere instruments have an overresponse in the intermediate-energy region which causes the dose-rate reading to be high by as much as 70 percent for reactor neutrons which contain a very high fraction of intermediate-energy neutrons. Around accelerators the contribution from intermediate-energy neutrons is usually negligible and the instrument reports a dose rate within the \pm 15 percent stated previously.

A recent calibration with $2.5 \mathrm{MeV}$ neutrons from a CockroftWalton accelerator gave a new point of $0.94 \mathrm{cts} / \mathrm{sec}$, which can be added to $\mathrm{Fig.} \mathrm{1.} \mathrm{A} \mathrm{recent} \mathrm{thermal} \mathrm{calibration} \mathrm{at} \mathrm{the} \mathrm{Water} \mathrm{Boiler}$ Reactor inaicated that our original calibration was high by about 
1 or 2 percent because of the gamma-ray sensitivity of the detector. The error is smaller than the uncertainty in the flux; therefore, no correction factor is given.

The single-sphere instruments may be calibrated with any energy of neutron source, although PuBe neutron sources are probably the easiest and most frequently used. These sources give a response which is lower than the desired calibration point by $\sim 22$ percent. Normally this factor is not considered, and the instruments are calibrated directly to PuBe neutrons. This results in an instrument which reads 22 percent high for all other neutrons, which is still reasonably accurate, and avoids the possibility of obtaining a low reading from a PuBe neutron source.

The original instrument's contained LiI crystals $4 \mathrm{~mm}$ in diameter and $4 \mathrm{~mm}$ thick; but recently crystals $8 \mathrm{~mm}$ in diameter and $4 \mathrm{~mm}$ thick have been used. The larger crystals increase the counting rate for neutrons by a factor of 2.88 over those shown in Fig. 1 . However, the gamma-ray sensitivity increases by a factor of 24 , which is undesirable for some locations where instruments are subjected to high gamma-ray fluxes or gamma-rays having energies greater than $4.0 \mathrm{MeV}$. Gamma-ray energies of greater than $4.0 \mathrm{MeV}$ are detected by both crystal sizes at much lower dose rates than those of ${ }^{6}{ }^{\circ} \mathrm{Co}$ where $1 \mathrm{R} / \mathrm{hr}$ presents no problem.

\section{OPERATING EXPERIENCE}

Several models of the $10 \mathrm{in.} \mathrm{sphere} \mathrm{neutron-instruments} \mathrm{are} \mathrm{in}$ use at the Los Alamos Scientific Laboratory. Portable instruments have been made (see Fig. 3) which are, unfortunately, fairly heavy

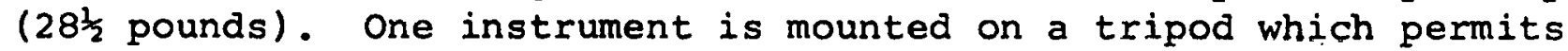
readings to be obtained at various heights around critical assemblies. Other instruments are permanently mounted on walls or on a stand (see Fig. 4). Readouts are either logarithmic or linear, depending on the preference of the operating group.

The chief cause for maintenance on the instruments has been crystal damage from moisture leaking in the crystal mount. The earlier crystals we received from the Harshaw Chemical company leaked moisture which was immediately absorbed by the crystal, changing its scintillation properties. However, after Harshaw developed a new technique of sealing, no crystal damage from moisture was observed.

Previously it had been observed that the instrument gain had to be increased or the discrimination point lowered after a few months of operation. At first, some of the electronic components were 
believed responsible, but now it has been determined that changes in the crystals are at least partially responsible for making the adjustments necessary:5 The crystals apparently reach a fixed point after a few months and no further adjustments due to crystal change are required.

Damage to one of the crystals was observed after the instrument had been exposed to neutron fluxes of up to $20,000 \mathrm{rem} / \mathrm{hr}$ for extended periods. In normal use, no damage due to gamma-ray or neutron radiation will be experienced.5

Some mechanical damage to the instruments has occurred because the portable units were dropped, and once a wind storm overturned an instrument mounted on a roof. In all cases these instruments were returned to service after the necessary repairs.

One of our operating groups which uses 12 of the instruments at an accelerator obtains a pulse-height analysis of each unit on a 6-months basis. Loss of gain attributed to photomultiplier tube changes and/or crystal changes is observed and corrected. This group reports essentially no maintenance or downtime for the instruments.

One reason the $10 \mathrm{in.} \mathrm{sphere} \mathrm{instrument} \mathrm{has} \mathrm{been} \mathrm{widely} \mathrm{accepted}$ at Los Alamos is that the response of the instrument is proportional to the rem dose. This eliminates the guesswork in determining the average neutron energy. Correction factors depending on neutron energy, which previously had to be applied to neutron measurements, are eliminated and no knowledge of the rem-dose curve is required. A person without previous training in monitoring can use one of the instruments to measure the dose rate of any neutron energy (less than 7.0 MeV) and report a reasonably arcurate neutron-dose rate.

\section{SPECIAL APPLICATIONS}

An attempt was made to measure neutrons from a burst, but the response of the instrument was not reliable. It was decided to continue using the polyethylene sphere, but to replace the crystal with a silver foil on the end of an end-window GM tube. A miniature GM tube that could be inserted in the ball was ohtained, and a $5 / 8$ in. diameter, $20 \mathrm{mil}$ thick silver foil was used. The GM tube was powered by a portable GM survey instrument and the signal fed from the earphone jack to a scaler.

A calibration for a silver foil was made with PuBe neutrons (corrected by +22 percent) and with $14.1 \mathrm{MeV}$ neutrons. For a burst of $<1$ sec duration, counts of $380 \mathrm{cts} / 2-\mathrm{min} / \mathrm{mrem} 10.016 \mathrm{cts} / 2-\mathrm{min}$ 
for $\left.1 \mathrm{n} / \mathrm{cm}^{2} / \mathrm{sec}\right)$ for PuBe neutrons and $99 \mathrm{cts} / 2-\mathrm{min} / \mathrm{mrem}(0.0069$ cts/2-min for $1 \mathrm{n} / \mathrm{cm}^{2} / \mathrm{sec)}$ for $14.1 \mathrm{MeV}$ neutrons were obtained. After the burst there was a second's delay before the count was started. The background for the GM tube was about $160 \mathrm{cts} / 2-\mathrm{min}$. The above calibrations are for a silver foil and may not be the same for a LiI crystal; see discussion below.

An indium foil was used in place of the crystal in another attempt to study the neutron dose rates from bursts. The results obtained by beta-ray counting the foil were $6 \mathrm{cpm} / \mathrm{mrem}$. By using a 3 in. $x 3$ in. NaI crystal and pulse height analysis, 1.5 cpm for the $1.27 \mathrm{MeV}$ gamma-ray was obtained. The sensitivity of this method is considerably less than that of the Ag foil-GM tube method described above, and the need for considerable supporting instrumentation makes the use of In foil difficult. It is, however, a technique which can be used.

Both indium and silver have cross sections which are different from the $1 / v$ cross section of lithium, and the response curve versus energy would be different if these materials were substituted for lithium. This has not been studied, and the use of these instruments is restricted to fast neutrons which vary in energy only slightly from the calibration sources and have only a small thermal and intermediate component.

To eliminate the sensitivity to high-energy gamma-rays; it was suggested that a spiral fission-foil counter be used. One of these counters was placed in a 10 in. sphere and exposed to PuBe neutrons. The sensitivity was adequate enough to encourage further study. The response of such an instrument over the entire energy spectrum was studied using the computer and found to be essentially the same as LiI crystals. Further study of this instrument is planned.

A large piece of cobalt was placed in the $10 \mathrm{in.} \mathrm{sphere} \mathrm{and}$ exposed to neutrons. The sensitivity of this instrument was too small to be useful. The lack of sensitivity is believed due to the cross section of $C o$, which has its major spike at an energy of 140 $\mathrm{eV}$ which is considerably above the energy of the neutrons in the center of the sphere. A smaller sphere would have to be used, and the response would not be proportional to the rem-dose curve.

Another adaption which has been used successfully at other laboratories is to use 1 ithium-6 and 1 ithium-7 thermoluminescent dosimeters in place of the LiI crystals. This adaption is useful if the gammaray flux is high or for bursts of neutrons. 
A 10 in. sphere has been designed which includes nested 2 in., 3 in.. and 8 in. spheres. This makes it possible to use the multisphere technique without having to carry four separate spheres.

\section{NEUTRON ENERGIES $<7.0 \mathrm{MEV}$}

The single-sphere instrument can be used for neutrons having energies above $7.0 \mathrm{MeV}$, but is then no longer rem equivalent. For neutrons of greater than $7.0 \mathrm{MeV}$ the response of the single-sphere instrument drops sharply until at $14 \mathrm{MeV}$ it is approximately half the desired response. In addition, the quality factor that must be applied changes at $10 \mathrm{MeV}$ (N.B.S. Handbook 63), which further decreases the accuracy of the instrument to measure neutrons of energies above $10 \mathrm{MeV}$. Care should be taken to calibrate the instrument to these higher energy neutrons. For monitoring, a calibration of this type is complicated by scattered and leakage neutrons which will be recorded at a different efficiency from those of the primary calibration beam. In situations where adequate shielding is provided to assure only a small component of neutrons above $7.0 \mathrm{MeV}$, the instrument can be used with a standard calibration.

For energies much greater than $7.0 \mathrm{MeV}$ a procedure has been studied at Los Alamos Scientific Laboratory which utilizes spheres as large as 20 in. 4

\section{CONCLUSIONS}

The response of the $10 \mathrm{in.} \mathrm{sphere} \mathrm{instrument} \mathrm{approximates} \mathrm{the}$ neutron dose rate within \pm 4 percent for thermal neutrons and within \pm 15 percent for fast neutron energies from 0.2 to $7.0 \mathrm{MeV}$. As the energy increases above $7.0 \mathrm{MeV}$, the instrument underestimates the dose rate by a rapidly increasing amount.

This instrument permits a monitor, or other persons, to make a quick and accurate measurement of the dose rate from neutrons of an unknown spectrum. The information obtained by this instrument is ordinarily much more accurate than that obtained with the thermal and fast neutron monitoring instruments used at many facilities. The uge of the single-sphere instrument should be considered, particularly if the neutron-energy spectrum is unknown or varies with time. 
REFERENCES

${ }^{3}$ Bramblett, R. I., Ewing, R. I.; and Bonner, T. W., "A New Type of Neutron Spectrometer," Nuclear Instr. and Methods, 9, 1 (1960).

${ }^{2}$ Hankins, Dale E.. A Neutron Monitoring Instrument Having a Response Approximately Proportional to the Dose Rate from Thermal to 7.0 Mev. USAEC Report LA-2717, Los Alamos Scientific Laboratory, March 1962.

${ }^{3}$ Carlson, B., Lee, C., and Worlton, J., The DSN and TDC Neutron Transport Code, USAEC Report LAMS-2346, Los Alamos Scientific Laboratory, October 1959.

${ }^{4}$ MCQuire, Stephen A.. A Dose Monitoring Instrument for Neutrons from Thermal to $100 \mathrm{MeV}$, USAEC Report Los Alamos Scientific Laboratory, in publication.

${ }^{5}$ Hankins, Dale E., Radiation Damage to the Scintillation Properties of Lithium-Iodide Crystals, USAEC Report LA-DC-7108, Los Alamos Scientific Laboratory (1965). 


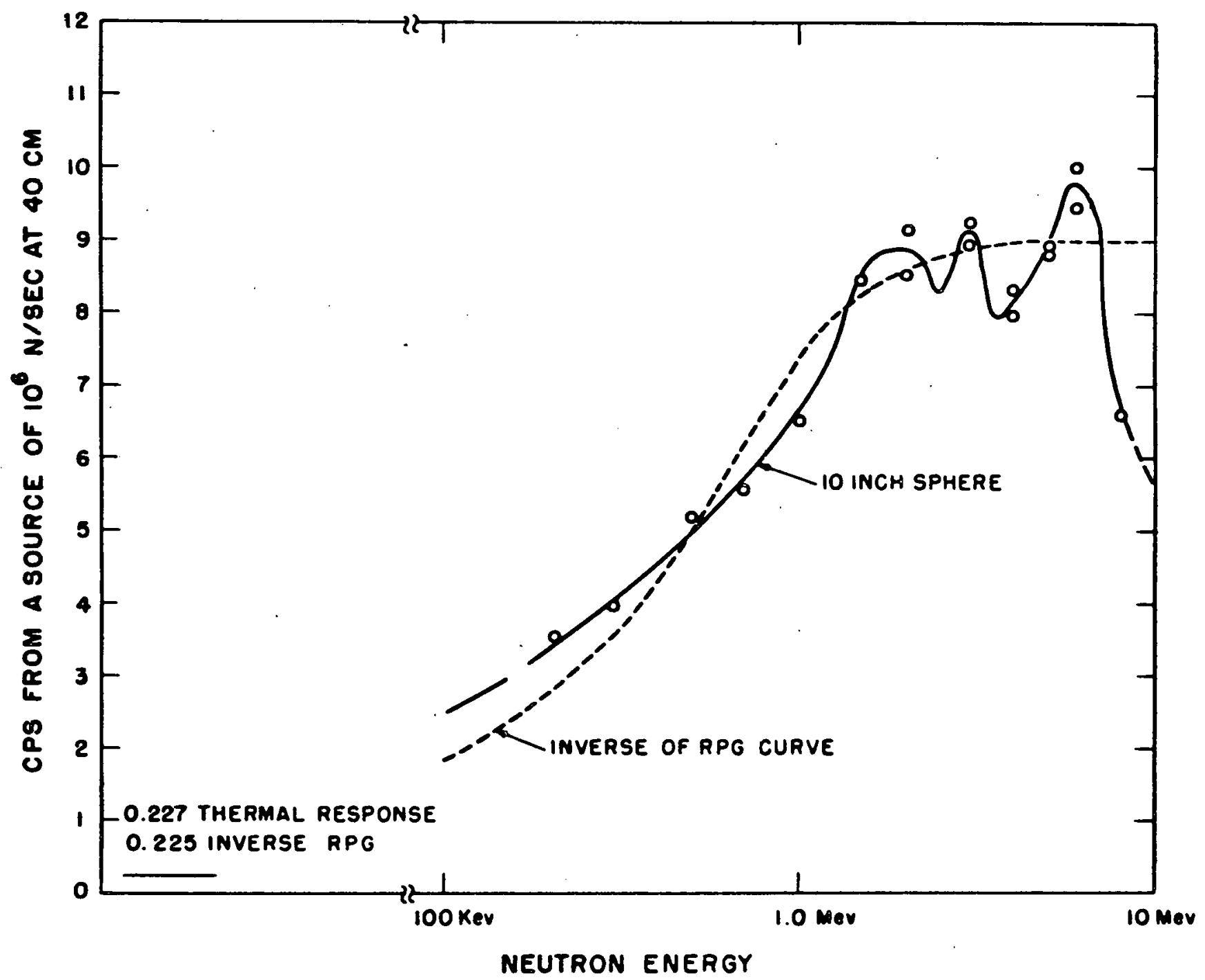

Fig. 1. Estimated response of a 10 in. single-sphere instrument vs energy (circles represent calibration points). 


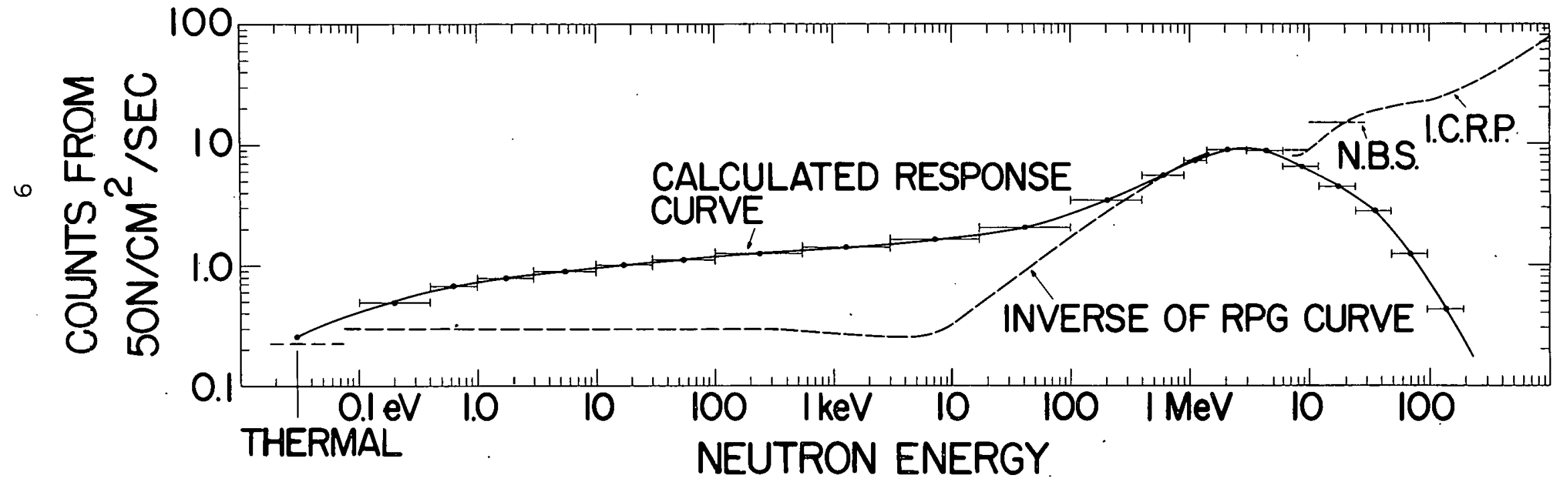

Fig. 2. Calculated response of a 10 in. single-sphere instrument vs energy. 


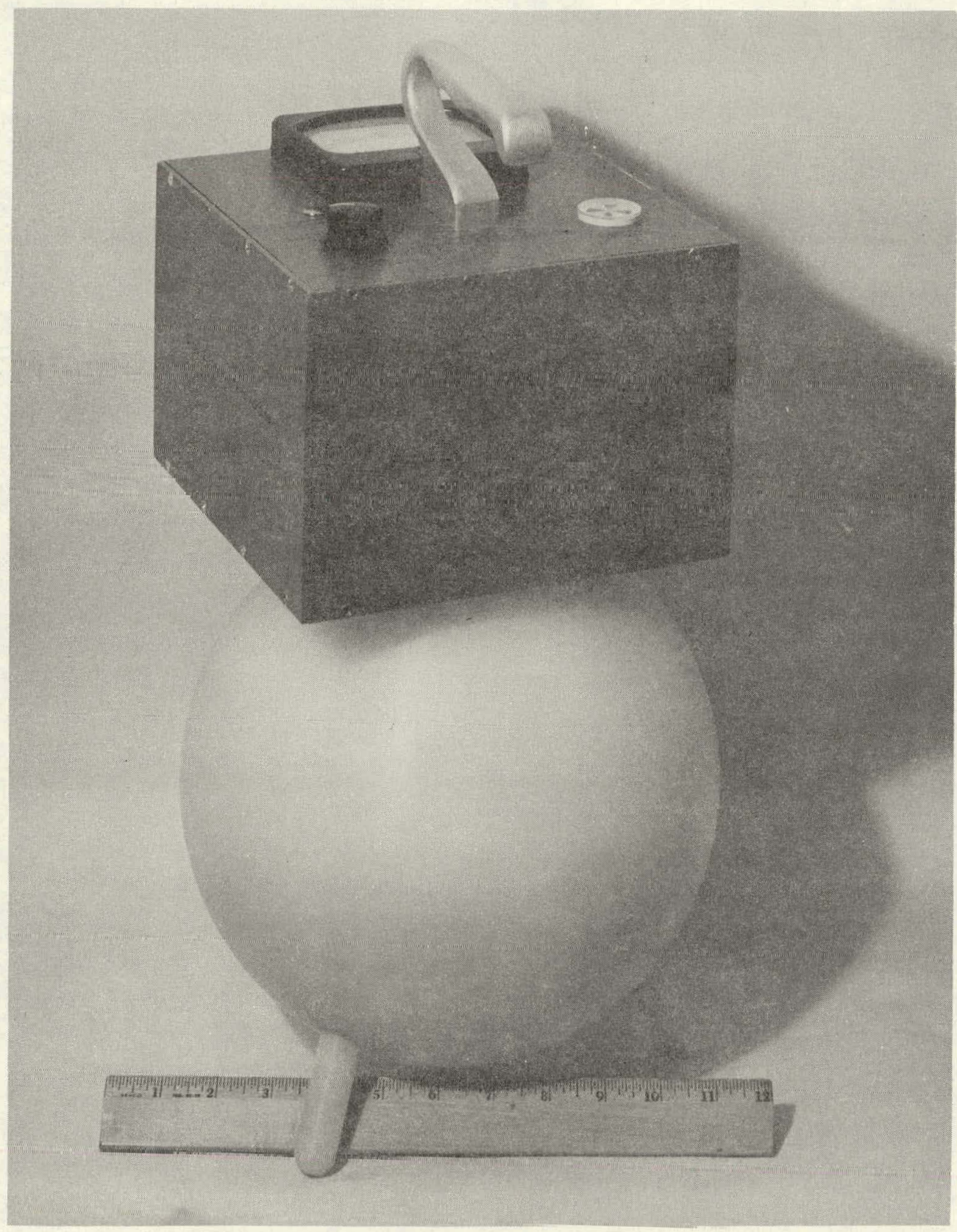

Fig. 3. A portable single-sphere neutron-monitoring instrument. 


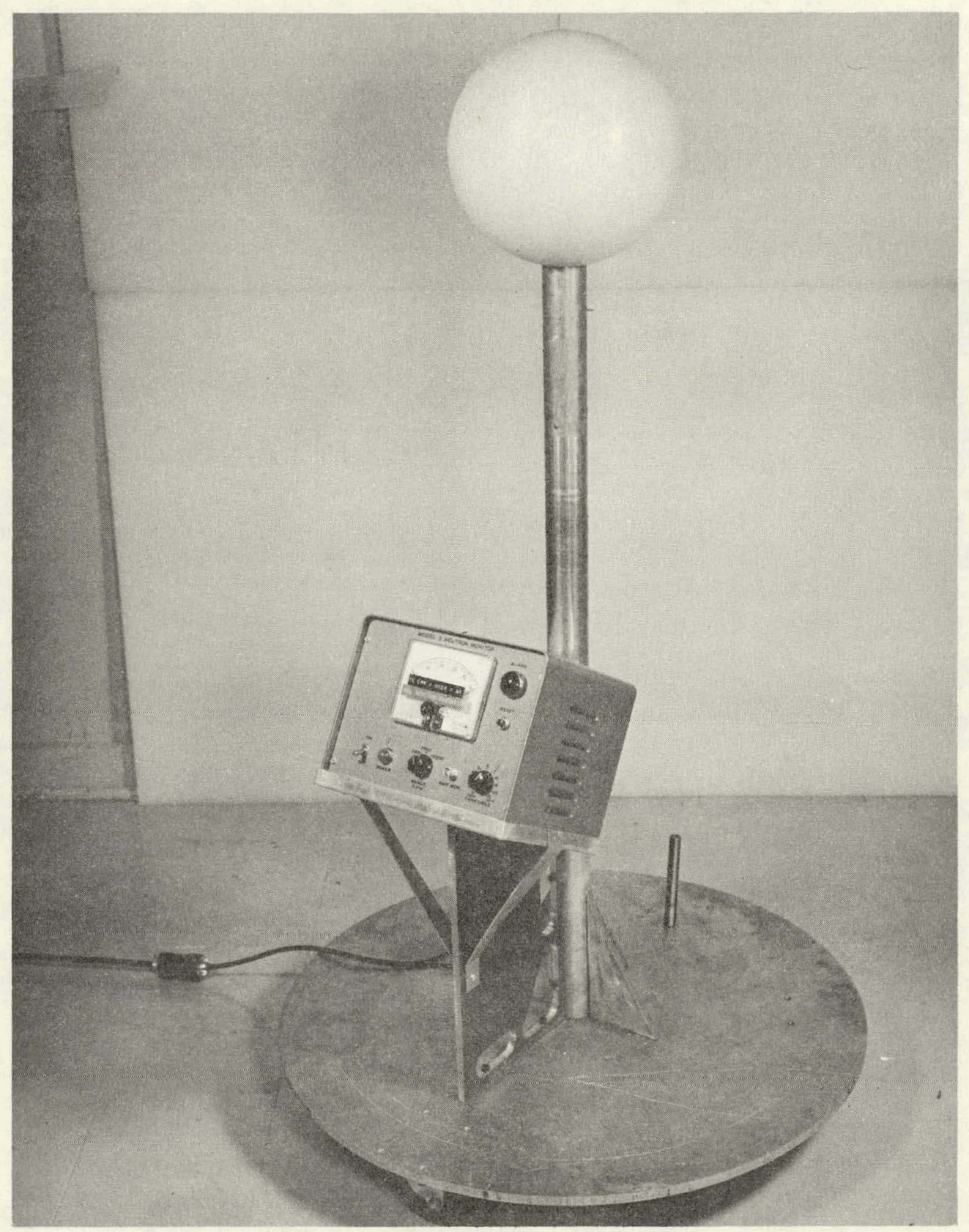

Fig. 4. An AC-powered single-sphere instrument mounted on a stand. 